\title{
Evaluating the Contribution of Serotonin Receptor Subtypes and 'Binge' 3,4-Methylenedioxymethamphetamine (MDMA) Exposure to the Discriminative Stimulus Effects of MDMA in Rats
}

\author{
V. Smithies* and J.H. Broadbear
}

School of Psychology and Psychiatry, Monash University, Australia

Keywords: 3,4-Methylenedioxymethamphetamine (MDMA), d-amphetamine, WAY 100,635, ritanserin, discriminative stimulus, rat.

\section{INTRODUCTION}

3,4-Methylenedioxymethamphetamine

(MDMA; 'Ecstasy') shares psychoactive effects with drugs that possess stimulant (e.g. amphetamine, the effects of which are primarily dopaminergic) and hallucinogenic properties (e.g. LSD, which has serotonergic effects) [1]. The majority of MDMA's distinctive effects as well as its toxicity have been linked to its actions on serotonergic neurotransmission [2]. One way in which MDMA's serotonergic effects can be studied is to train rats to distinguish dopaminergic stimulant effects from mood and perception-altering serotonergic effects using a three-way drug discrimination paradigm [3].

\section{METHOD}

Male and female Sprague Dawley rats were trained to reliably differentiate between d-amphetamine $(0.75 \mathrm{mg} / \mathrm{kg})$, MDMA $(1.5 \mathrm{mg} / \mathrm{kg})$ and saline. The contributions of serotonin $_{1 \mathrm{~A}}$ and serotonin $2 \mathrm{~A} / \mathrm{C}$ (5- $\mathrm{HT}_{1 \mathrm{~A}}$ and $\left.5-\mathrm{HT}_{2 \mathrm{~A} / \mathrm{C}}\right)$ receptors to MDMA's interoceptive effects were then evaluated. This was done both before and after the rats were exposed to an MDMA 'binge' (3 x 10mg/kg MDMA injections given at two hourly intervals) to determine whether a reportedly neurotoxic dosing regimen [4] would disrupt the interoceptive cues of MDMA.

Table 1. Frequency and Percent of Choice of MDMA, AMP, and SAL Levers for First Completed Fixed Ratio (FR=10 Lever Presses) in Response to MDMA (1.5mg/kg) Alone or in Combination with Ritanserin (1.5mg/kg and 3mg/kg;) or WAY $100,635(1 \mathrm{mg} / \mathrm{kg})$

\begin{tabular}{|c|c|c|c|c|c|c|}
\hline \multirow{2}{*}{ Lever } & \multicolumn{2}{|c|}{ MDMA (n=10) } & \multicolumn{2}{c|}{+ Ritanserin $(\mathrm{n}=\mathbf{8})$} & \multicolumn{2}{c|}{ WAY100,635 (n=10) } \\
\cline { 2 - 7 } & Frequency & Percent & Frequency & Percent & Frequency & 8 \\
\hline \hline MDMA & 10 & 100 & 5 & 02.5 & 0 & 0 \\
\hline AMP & 0 & 0 & 0 & 37.5 & 2 \\
\hline SAL & 0 & 0 & 3 & 0 & 20 \\
\hline
\end{tabular}

Table 2. Frequency and Percent of Choice of MDMA, AMP, and SAL Levers for First Completed Fixed Ratio (FR=10 Lever Presses) in Response to MDMA (1.5mg/kg) Administration Post Binge

\begin{tabular}{|c|c|c|c|c|c|c|}
\hline \multirow{2}{*}{$\begin{array}{c}\text { Lever } \\
(\mathbf{n}=6)\end{array}$} & \multicolumn{2}{|c|}{ Post-Binge Day 2 } & \multicolumn{2}{c|}{ Post-Binge Day 5 } & \multicolumn{2}{c|}{ Post-Binge Day 8 } \\
\cline { 2 - 7 } & Frequency & Percent & Frequency & Percent & Frequency & Percent \\
\hline \hline MDMA & 3 & 50 & 4 & 66.7 & 0 & 0 \\
\hline AMP & 1 & 16.7 & 0 & 0 & 2 & 33.3 \\
\hline SAL & 2 & 33.3 & 2 & 33.3 & 2 \\
\hline
\end{tabular}

*Address correspondence to this author at the School of Psychology and Psychiatry, Monash University, Australia; Tel: +613 9905 3903; Fax: +613 9905 3948; E-mail: vanessa.smithies@monash.edu

\section{RESULTS}

Blockade of $5-\mathrm{HT}_{1 \mathrm{~A}}$ or $5-\mathrm{HT}_{2 \mathrm{~A} / \mathrm{C}}$ receptors, via administration of WAY $100,635(1 \mathrm{mg} / \mathrm{kg})$ or ritanserin $(1.5$ and $3 \mathrm{mg} / \mathrm{kg}$ ), significantly disrupted MDMA-appropriate 
responding, as evident from the variability in the training drug-appropriate lever on which the first response ratio was completed (see Table 1). Binge MDMA exposure also resulted in selective disruption to the MDMA training cue during the subsequent 8 days (see Table 2). Once the discrimination had recovered, repeating the antagonist tests revealed that the disruptions by the $5-\mathrm{HT}_{1 \mathrm{~A}}$ and $5-\mathrm{HT}_{2 \mathrm{~A} / \mathrm{C}}$ receptor antagonists to MDMA's discriminative cues were not significantly different to what was measured prior to the 'binge'.

\section{DISCUSSION}

Co-administration of MDMA with $5-\mathrm{HT}_{1 \mathrm{~A}}$ and $5-\mathrm{HT}_{2 \mathrm{~A} / \mathrm{C}}$ antagonists, WAY and ritanserin interrupted the interoceptive cues that rats used to discriminate MDMA from amphetamine, which is consistent with findings from other studies $[3,5]$. This implies that for some rats the discriminative stimulus effects of MDMA were mediated by $5-\mathrm{HT}_{1 \mathrm{~A}}$ and/or $5-\mathrm{HT}_{2 \mathrm{~A} / \mathrm{C}}$ mechanisms of action. The MDMA 'binge' dosing regimen resulted in a transient reduction in MDMA-appropriate lever responding that continued to be disrupted in a third of subjects at least 8 days later (persisting for 16 and 69 days in the remaining 2 rats). This suggests that MDMA's discriminative stimulus effects were disrupted following high-dose MDMA administration, consistent with previous evidence of alterations in 5-HT neurotransmission after MDMA exposure [2]. The discrimination did recover over time however, supporting the suggestion that the neuronal effects of high-dose exposure may be transient [6]. Binge administration did not influence the contributions of $5-\mathrm{HT}_{1 \mathrm{~A}}$ and5- $\mathrm{HT}_{2 \mathrm{~A} / \mathrm{C}}$ receptor activation to MDMA's discriminative cues, which provides preliminary evidence to suggest that the recovered 'discrimination' was based on the same interoceptive cues as the pre-binge discrimination.

\section{CONCLUSION}

This study provides support for the importance of 5$\mathrm{HT}_{1 \mathrm{~A}}, 2 \mathrm{~A} / \mathrm{C}$ mediated cues in the discriminative, and by extension behavioural and neurotoxic effects of MDMA, and suggests that MDMA's discriminative stimulus effects are only temporarily disrupted following high-dose MDMA exposure.

\section{REFERENCES}

[1] Fantegrossi WE. In vivo pharmacology of MDMA and its enantiomers in rhesus monkeys. Exp Clin Psychopharmacol 2008; 16(1): 1-12.

[2] Capela J, Carmo H, Remião F, Bastos M, Meisel A, Carvalho F. Molecular and cellular mechanisms of ecstasy-induced neurotoxicity: an overview. Mol Neurobiol 2009; 39(3): 210-71.

[3] Goodwin AK, Baker LE. A three-choice discrimination procedure dissociates the discriminative stimulus effects of d-Amphetamine and $( \pm)$ MDMA in rats. Exp Clin Psychopharmacol 2000; 8(3): 415-23.

[4] Baumann MH, Wang X, Rothman RB. 3, 4-Methylenedioxymethamphetamine (MDMA) neurotoxicity in rats: a reappraisal of past and present findings. Psychopharmacology 2007; 189: 407-24.

[5] Glennon RA, Higgs R, Young R, Issa H. Further studies on Nmethyl-1 (3, 4-methylenedioxyphenyl) -2-aminopropane as a discriminative stimulus: antagonism by 5-hydroxytryptamine 3 antagonists. Pharmacology Biochem Behav 1992; 43(4): 1099-106.

[6] Wang X, Baumann MH, Dersch CM, Rothman RB. Restoration of 3, 4-methylenedioxymethamphetamine-induced 5-HT depletion by the administration of 1-5-hydroxytryptophan. Neuroscience 2007; 148(1): 212-20. 